\title{
LA CRISIS DEL DERECHO INTERNACIONAL DE INVERSIONES EXTRANJERAS: PROPUESTAS DE REFORMA
}

\section{A CRISE DO DIREITO INTERNACIONAL DOS INVESTIMENTOS ESTRANGEIROS: PROPOSTAS DE REFORMA}

Omar E. García-Bolívar

Resumen: Este ensayo describe el sistema internacional de protección de las inversiones extranjeras destacando sus elementos y características esenciales. Paralelamente se presentan las críticas sustentadas con razones $y$ hechos. El objetivo ulterior del ensayo es presentar propuestas de reformas al Derecho Internacional de Inversiones, incluyendo la creación de un Tribunal Permanente de Inversiones.

Resumo: Esse ensaio descreve o sistema internacional de proteção dos investimentos estrangeiros destacando seus elementos e características essenciais. Paralelamente, apresentam-se críticas sustentadas em razões e fatos. O objetivo posterior ao ensaio é apresentar propostas de reforma ao Direito Internacional dos Investimentos, incluindo a de criação de um Tribunal Internacional de Investimentos.

Palabras clave: Derecho internacional de inversiones extranjeras, Arbitraje internacional de inversiones, Tribunal Permanente de Inversiones

Palavras-chave: Direito internacional dos investimentos estrangeiros, Arbitragem internacional de investimentos, Tribunal Permanente de Investimentos

\section{INTRODUCCIÓN}

El Derecho Internacional Público ha sufrido transformaciones recientesquellevan a cuestionar el funcionamiento de antiguos conceptos. Así ha sucedido en disciplinas que son especies dentro del género

\footnotetext{
* Abogado internacional, árbitro y consultor de políticas públicas. Es Presidente de BG Consulting Inc, firma consultora basada en Washington, D.C. especializada en Derecho y desarrollo. Ha asesorado y educado en países en América, Asia, África y Europa Oriental en reformas legales de inversiones. E-mail: omargarcia@bg-consulting.com
} 
amplísimo de esa rama del Derecho, tales como el Derecho Internacional Ambiental, el Derecho Internacional de Telecomunicaciones y el que nos toca desarrollar en este ensayo, el Derecho Internacional de Inversiones Extranjeras.

Nutridos del devenir de la globalización económica, se fueron tomando conceptos consagrados del Derecho Internacional Público como la responsabilidad de los Estados por daños a los extranjeros y se desarrollaron una serie de tratados que consagraban por un lado derechos a unas figuras que hasta entonces no eran actores internacionales jurídicamente hablando, como lo eran los inversionistas extranjeros, a la par que les otorgaban un instrumento inédito, cual era la posibilidad de demandar satisfacción judicial internacional a los Estados por acciones $\mathrm{u}$ omisiones internas.

DeestaformafueconcebidoelDerechoInternacionaldeInversiones Extranjeras: originalmente como una evolución consensuada entre Estados a manera de superar lo que algunos percibían como escollos, tales como el argumento según el cual las disputas de los extranjeros en contra de los Estados habrían de ser resueltas en instancias locales y la soberanía absoluta sobre los recursos naturales.

Sin embargo, al cabo de casi cinco décadas de experiencias de ese sistema, la evaluación es mixta. Por un lado está la creación de un sistema pacífico de resolución de disputas internacional. Pero por otro lado se percibe un sistema poco legítimo y con demasiada autoridad, habiéndose constituido en lo más parecido a un tribunal internacional constitucional, con capacidad de revisar, adjudicar y compensar ${ }^{1}$. Adicionalmente, el desbalance entre los deberes de los Estados y la inexistencia de los deberes de los inversionistas extranjeras, se aúna a una serie de críticas cada vez más sonoras, que van desde la falta de consistencia de las decisiones hasta el exagerado costo y la falta de transparencia de los procedimientos de resolución de disputas. Por ello, que cada vez más sean los países que pasan de la crítica a la acción previniendo su exposición al sistema internacional de protección de inversionistas extranjeros e incluso separándose de él, no ha de ser ninguna sorpresa.

El propósito de este ensayo es describir los problemas que enfrenta el actual Derecho Internacional de Inversiones Extranjeras, a la par de presentar ciertas recomendaciones de reformas viables en el contexto del proceso de integración de América del Sur.

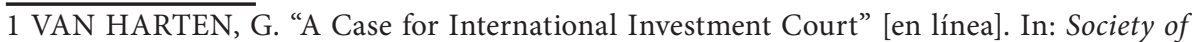
International Economic Law (SIEL) Inaugural Conference 2008 Paper, (June 30 2008) [en línea]. [consultada febrero de 2015]. Disponible en: <http://papers.ssrn.com/sol3/papers. cfm?abstract_id=1153424>. 


\section{ORIGEN DEL DERECHO INTERNACIONAL DE INVERSIONES}

El Derecho Internacional de Inversiones consiste en un conjunto de reglas que protegen a la inversión y al inversionista extranjero frente a las acciones de los Estados receptores de la inversión. El desiderátum de ese Derecho ha sido que mediante la protección internacional a la inversión, los inversionistas se sentirían más seguros y en consecuencia atraídos a realizar inversiones en los Estados que se obligaran por esas reglas.

Buena parte de ese Derecho se encuentra consagrado en los Tratados Bilaterales de Inversiones -TBIs o BITs por sus siglas en inglés- y los tratados multilaterales que abordan el tema inversión, ya sea como parte de un tratado de comercio, de manera regional o como uno de los aspectos críticos de inversiones extranjeras, tales como el de las garantías contra riesgo no comercial o el que crea un centro para solución de disputas de inversiones.

Los TBIs y los otros tratados donde se consagra parte sustancial del Derecho Internacional de Inversiones han sido producto de acuerdo de voluntad de los Estados, donde unos interesados en proteger el capital de sus nacionales han aceptado y logrado que los otros - los interesados en financiar su desarrollo- acepten reglas que benefician a unos terceros: los inversionistas extranjeros.

Para el inversionista, la inversión es una forma de maximizar ganancias, expandir mercados, consolidar alianzas estratégicas, desarrollar etapas del proceso productivo o cualquier otra de índole empresarial. Y el Derecho Internacional de Inversiones Extranjeras es un mecanismo de protección, no solo con la inclusión de estándares específicos de protección en contra ciertas acciones del Estado, sino con la inclusión de la posibilidad de demandar directamente al Estado anfitrión ante instancias internacionales.

Para el Estado receptor la inversión es una especie dentro de un género, el de fondos útiles para financiar el desarrollo. En ese género estarían también la renta sea de recursos naturales o de tributos, los créditos yla ayuda internacional. En otras palabras, para el Estado receptor de la inversión, la inversión extranjera no es más que un mecanismo de financiamiento del desarrollo, i.e., crecimiento económico, obtener tecnología de avanzada, activar el aparato productivo, crear empleos, disminuir la pobreza, entre otros. Y el Derecho Internacional de Inversiones consiste en un mecanismo de promoción de esas inversiones.

Esa diferencia de intereses ha sido históricamente una fuente de disputas para las cuales se han empleado diferentes instrumentos legales, algunos a nivel de doctrinas o teorías, otros a nivel de textos legales. Así, por ejemplo, los Estados han usado instrumentos como la Carta de los Derechos y Deberes Económicos de los Estados postulada por las 
Naciones Unidas ${ }^{2}$ y la doctrina Calvo según la cual los inversionistas extranjeros no tienen derecho a someter disputas con los Estados anfitriones a instancias internacionales, sino que se deben sujetar a los tribunales locales. Los inversionistas han usado doctrinas tales como la de Responsabilidad de los Estados por Lesiones a los Extranjeros, y fórmulas de compensación total y a valor de mercado en casos de expropiaciones directas o indirectas.

Hasta 1959, los relaciones entre los inversionistas extranjeros se regían única y exclusivamente por el Derecho Internacional Público, donde ante algún maltrato al inversionista extranjero por parte del Estado anfitrión, el inversionista tenía dos opciones. La primera, demandar al Estado ante los tribunales locales. Ante esa opción el argumento ha sido, entre otros, que la protección otorgada por el Derecho local no es suficiente. El Estado, en ejercicio de su soberanía, podría modificar o eliminar esa protección sin mayor limitación ${ }^{3}$.

La segunda opción disponible al inversionista extranjero era solicitar al Estado de su nacionalidad protección diplomática, por lo cual el Estado de nacionalidad y el anfitrión podían negociar y eventualmente encontrarse como partes de una acción ante la Corte Internacional de Justicia o su antecesora la Corte Permanente Internacional de Justicia.

Pero en 1959 se suscribió el primer tratado de protección de inversiones extranjeras entre Alemania y Pakistán. Ese tratado era una evolución de los tratados de amistad, comercio y navegación y aunque no contenía muchas de las protecciones que hoy día se observan en los tratados en cuestión, creó el paradigma de lo que después se convertiría en un sistema integrado de protección al inversionista y a la inversión extranjera. Hoy día existen más de 3000 tratados de esa naturaleza, más capítulos de inversiones en tratados de libre comercio, siendo que la mayoría de estos tratados están suscritos entre países desarrollados y países en desarrollo o entre países en desarrollo, con pocos tratados suscritos entre países desarrollados.

Paralelamente y bajo los auspicios del Banco Mundial, se suscribió en el año 1966 la Convención que creó el Centro Internacional de Arreglos de Disputas de Inversiones -en lo sucesivo CIADI o Centro y la Convención, también conocida como la Convención de Washington- ${ }^{4}$ el cual cumplidas ciertas condiciones puede dilucidar las disputas legales de inversiones que se susciten entre el inversionista extranjero y

2 NACIONES UNIDAS. Carta de los Derechos y Deberes Económicos de los Estados, 12 de diciembre de 1974. Resolución 3281 (xxix) de la Asamblea General de la ONU [en línea]. [consultada en febrero de 2015]. Disponible en: <http://biblio.juridicas.unam.mx/ libros/1/353/57.pdf $>$.

3 GARCÍA-BOLÍVAR, Omar E. "Sovereignty vs. Investment protection: back to Calvo?" ICSID Rev. 2009, n 2, p. 446.

4 ICSID. Convención del Centro Internacional de Arreglo de Disputas de Inversiones. (10 Sept. 1964), 1 U.S.T. 1270, 4 I.L.M. 524. [consultada en febrero de 2015]. Disponible: <https://icsid. worldbank.org/ICSID/StaticFiles/basicdoc/CRR_English-final.pdf>. 
el Estado anfitrión.

De esta manera surgió un mecanismo para solucionar disputas entre un Estado contratante a la Convención y un inversionista de otro Estado contratante, mediante conciliación o arbitraje. Ese mecanismo permaneció silente por décadas, hasta que en los años 90 comenzó a ser utilizado por los inversionistas. A partir de esos años se comenzaron a presentar en promedio cerca de 2 casos por año, hasta un momento cuando se presentaron más de 50 casos en un año ${ }^{5}$.

Una de las razones que motivó el surgimiento de los TBI en donde se extendía la protección a los inversionistas extranjeros a distintos supuestos de hecho y se les daba la posibilidad de demandar directamente al Estado anfitrión ante un tribunal arbitral internacional, fue el resultado del caso Barcelona Traction ventilado por ante la Corte Internacional de Justicia.

En Barcelona Traction ${ }^{6}$ una compañía registrada en Canadá pero cuyas acciones eran propiedad de ciudadanos Belgas había sido expropiada por el Reino de España. Bélgica otorgó protección diplomática a sus ciudadanos y demandó a España por ante la Corte Internacional de Justicia.

La Corte indicó que el Derecho Internacional reconoce la existencia de la entidad corporativa como un asunto del Derecho local ocasionado por la realidad económica y determinó que Bélgica no podía proteger a una compañía en una acción en contra de España. La decisión se basó en que bajo el Derecho Internacional consuetudinario, una compañía puede reclamar la protección del Estado en el cual está registrada pero no la protección del Estado del cual los accionistas son ciudadanos. Sin embargo, en ese caso, Canadá rechazó otorgar protección diplomática porque para ellos no era suficiente el registro de la compañía en Canadá, sino que además se hacía necesario que la compañía hubiera generado un beneficio económico sustancial o que la compañía hubiera tenido algún interés económico de carácter sustancial.

El remedio encontrado para evitar que decisiones similares a Barcelona Traction evitaran la protección internacional a la subsidiaria de un inversionista extranjera, fue incluir disposiciones expresas en los TBI según las cuales las subsidiarias de un inversionista extranjero tendrían la nacionalidad del inversionista extranjero, independientemente del lugar de registro de la subsidiaria e incluso si ésta se hubiera registrado en el Estado anfitrión.

5 ICSID Caseload Statistics, 2014-2, [consultada en febrero de 2015]. Disponible en. $<$ https:// icsid.worldbank.org/apps/ICSIDWEB/resources/Documents/ICSID\%20Web\%20Stats\%20 2014-2\%20(English).pdf $>$.

6 Barcelona Traction, Light and Power Company Limited - Bélgica c. España-, 1970 I.C.J. 3, Decisión de 5 de Febrero de 1970. 


\section{EL DERECHO INTERNACIONAL DE INVERSIONES EXTRANJERAS: ¿QUÉ REGULA?}

A pesar que el grueso del Derecho Internacional de Inversiones no está condensado en un solo instrumento multilateral, hay ciertos aspectos que son comunes a la mayoría de los TBIs:

Se define qué tipo de inversión extranjera va a ser objeto de protección.

Aunque la tendencia mayoritaria es otorgar protección la inversión extranjera directa -vale decir aquella que tiene carácter de permanencia y respecto a la cual el inversionista mantiene el control- algunos TBIs contienen definiciones amplias que extiende protección a otros tipos de inversión, tales como las inversiones de carteras o formas de inversión heterodoxas, tales como las formas contractuales de franquicia o de producción compartida. Algunos contienen una lista negativa que excluye ciertos tipos de inversión de la protección internacional acordada.

Se define al inversionista extranjero.

Con frecuencia los TBIs definen al inversionista extranjero a las personas naturales o jurídicas que tengan la nacionalidad del Estado no receptor de la inversión. Sin embargo cuando se trata de personas jurídicas, los TBIs indican el criterio para definir la nacionalidad de éstas, el cual con frecuencia es el del lugar de registro. Igualmente, existe una tendencia mayoritaria de considerar nacionales del Estado del inversionista a las subsidiarias del inversionista extranjera registradas en el Estado anfitrión, siempre que se mantengan bajo su control.

Se otorga protección en contra de las expropiaciones que no cumplan ciertas condiciones.

A pesar que se reconoce la autoridad de los Estados para expropiar, se la somete a las condiciones que sea realicen por causa de utilidad pública, de manera no discriminatoria y mediante compensación justa, adecuada y oportuna. Igualmente se extiende el criterio a medidas equivalentes a la expropiación, en lo que los comentaristas denominan expropiaciones paulatinas o regulatorias.

Se garantiza al inversionista ciertos estándares de tratamiento.

La mayoría de los TBIs indican que los inversionistas extranjeros 
tienen garantizado un tratamiento igual a los nacionales en condiciones semejantes. También se establece un trato de nación más favorecida por el cual el inversionista extranjero tendría derecho a un tratamiento más favorable otorgado por el Estado anfitrión a inversionistas de otro Estado en otros tratados. Igualmente se otorgan garantías para que los inversionistas tengan un tratamiento justo y equitativo, sin que se defina qué se entiende por tales términos. En ciertos casos se otorgan garantías de protección y seguridad física.

Se establecen mecanismos de solución de disputas entre los inversionistas y los Estados anfitriones.

La mayoría de los TBIs contienen disposiciones según las cuales ante el surgimiento de diferencias con el Estado anfitrión los inversionistas pueden optar por negociar o presentar el caso ante una instancia de arbitraje internacional. Con frecuencia se indica que no es necesario agotar la instancia local. Algunos indican que si se opta por la instancia local luego no se podrá presentar reclamo por ante la instancia internacional. La gran mayoría contiene el consentimiento de los Estados partes en someter las disputas a arbitraje internacional. En algunos casos se indica que el arbitraje será administrado según la Convención CIADI, o se indica otro centro como la Cámara Internacional de Comercio (CII o ICC por sus siglas en inglés).

Se establecen cláusulas paraguas y otras disposiciones.

Muchos TBIs contienen disposiciones paraguas según las cuales es considerado violación del tratado el incumplimiento por parte del Estado anfitrión de cualquier de sus obligaciones, sean estas de naturaleza legal o contractual. Así, por ejemplo, ante un supuesto incumplimiento contractual por parte del Estado anfitrión, el inversionista tiene la posibilidad de intentar dos acciones: una de naturaleza contractual y otra derivada del TBI. Igualmente se establecen disposiciones diversas, tales como las que garantizan la libre transferencia de los dividendos y la repatriación de capitales en moneda de libre conversión y la de poder trasladar empleados de la nacionalidad del inversionista extranjero al Estado anfitrión.

\section{DISPUTAS DE INVERSIONES}

Como consecuencia del surgimiento del Derecho Internacional de Inversiones Extranjeras y la consagración del arbitraje de inversionistas extranjeros en contra de Estados, ha surgido todo un sistema de solución de controversias de inversiones extranjeras que cuenta con 
principios propios, expresamente indicados en la Convención CIADI o en los TBIs, o desarrollados jurisprudencial y doctrinariamente, entre los cuales destacan los siguientes:

El arbitraje de inversiones es respecto a disputas legales de inversiones.

El arbitraje internacional de inversiones es un mecanismo de solución de controversias legales relativas a inversiones entre el Estado anfitrión y un inversionista de otra nacionalidad. Esto supone que este arbitraje es para disputas solo de naturaleza legal, vale decir sobre derechos e intereses y no para disputas de naturaleza técnica, como puede ocurrir por ejemplo, en materia de la construcción sobre disputas relativas a las dimensiones de una tubería. Igualmente, el arbitraje debe ser estrictamente sobre materia de inversiones, y no sobre temas de comercio. Y la disputa debe ser entre un Estado y un extranjero, no entre un Estado y sus nacionales. condiciones.

El arbitraje de inversiones ante CIADI está sujeto a ciertas

El arbitraje internacional de inversiones ante el CIADI requiere que el Estado parte y el Estado de la nacionalidad del inversionista sean parte de la Convención de CIADI, y que ambas partes hayan otorgado su consentimiento a resolver la disputa por ante ese centro. Sin embargo, CIADI dispone del mecanismo complementario de resolución de disputas de inversiones, mediante el cual existe la posibilidad que si uno de los dos Estados no es parte de la Convención, más no los dos, y las partes en conflicto han otorgado el consentimiento arbitral, entonces pueden acceder a resolver la disputa ante ese mecanismo de CIADI.

Hay otros tipos de arbitrajes de inversiones.

La resolución de disputas de inversiones planteadas ante otros centros arbitrales o planteadas a través de arbitrajes ad-hoc solo requiere del consentimiento de las partes. Así sucede con disputas legales de inversiones entre Estados anfitriones e inversionistas planteadas por ante la Corte de Arbitraje de la CCI, la Corte de Londres de Arbitraje Internacional (LCIA por sus siglas en inglés), y el arbitraje ad-hoc entre inversionistas y Estados según las reglas del Comisión de las Naciones Unidas para el Derecho Mercantil Internacional (CNUDMI o UNCITRAL por sus siglas en inglés).

El arbitraje de inversión está sujeto a una legislación específica. 
La resolución de controversias mediante arbitraje en CIADI requiere que el tribunal arbitral se ciña a lo indicado por la Convención CIADI, a lo expresado por las partes en su consentimiento arbitral y a la legislación aplicable a la controversia. Con frecuencia, si la disputa versa sobre una violación de normas de Derecho Internacional, tales como las que recogen los TBIs, el tribunal aplicará las disposiciones del tratado relevante al caso. Pero es posible que la disputa de inversiones extranjeras verse sobre el incumplimiento de algún contrato entre inversionista y Estado, en cuyo caso el tribunal habrá de considerar las disposiciones contractuales y las disposiciones de la legislación a la cual está sujeto el contrato en cuestión ${ }^{7}$.

\section{El objetivo de la Convención CIADI.}

La Convención CIADI establece que la finalidad del centro es servir de mecanismo de resolución de disputas entre Estados soberanos e inversionistas extranjeros, con miras a crear un incentivo positivo para la atracción de inversiones extranjeras, a la par que se propende al desarrollo económico delos países signatarios. De esta manera, el Informe de los Directores Ejecutivos acerca de la Convención sobre Arreglo de Diferencias Relativas a Inversiones entre Estados y Nacionales de Otros Estados, indica: "Al presentar a los gobiernos el convenio que se adjunta, los Directores Ejecutivos están impulsados por el deseo de fortalecer la asociación de los países en la causa del desarrollo económico. La creación de una institución destinada a facilitar el arreglo de diferencias relativas a inversiones entre Estados e inversionistas extranjeros puede constituir un paso importante para promover un ambiente de confianza mutua y, por consiguiente, estimular el libre flujo de capital privado internacional hacia los países que desean atraerlo"8. Ese objetivo es relevante para la interpretación de esa Convención a tenor del artículo 31 de la Convención de Viena sobre el Derecho de los Tratados la cual dispone que "un tratado será interpretado de buena fe de acuerdo con el significado ordinario que se le dé a los términos del tratado en el contexto y con miras a su objetivo y propósito"

7 Artículo 42 de la Convención CIADI:

(1) El Tribunal decidirá la diferencia de acuerdo con las normas de derecho acordadas por las partes. A falta de acuerdo, el Tribunal aplicará la legislación del Estado que sea parte en la diferencia, incluyendo sus normas de derecho internacional privado, y aquellas normas de derecho internacional que pudieren ser aplicables.

(2) El Tribunal no podrá eximirse de fallar so pretexto de silencio u oscuridad de la ley.

(3) Las disposiciones de los precedentes apartados de este Artículo no impedirán al Tribunal, si las partes así lo acuerdan, decidir la diferencia ex aequo et bono.

8 Reporte de los Directores Ejecutivos del Banco Internacional para la Reconstrucción y Desarrollo sobre la Convención, 18 de marzo de 1965. [consultada en febrero de 2015]. Disponible en: <https://icsid.worldbank.org/ICSID/StaticFiles/basicdoc/CRR_English-final. pdf $>$.

9 NACIONES UNIDAS. Convención de Viena sobre el Derecho de los Tratados, artículo 31. 


\section{CRÍTICAS AL SISTEMA INTERNACIONAL DE PROTECCIÓN DE INVERSIONES EXTRANJERAS ${ }^{10}$}

Desde que se suscribió el primer TBI de la historia a la fecha, son muchos los cambios que ha experimentado el Derecho Internacional de Inversiones. Los múltiples TBIs o capítulos de inversiones en tratados de libre comercio vigentes entre distintos países del mundo, han creado una red de reglas que se complementan y sobreponen en aras de la protección del inversionista extranjera y de la inversión extranjera.

Hoy, es posible decir que el sistema internacional de protección de inversiones extranjeras ha sido probado una y otra vez. El veredicto es mixto. Por un lado hay quienes vanaglorian la virtud de haber despolitizado las disputas entre inversionistas y Estados creando un mecanismo ante el cual estas se puedan resolver de forma imparcial. Por otro lado hay un cúmulo de críticas al sistema que resumimos de seguidas.

\subsection{Los inversionistas son los principales beneficiarios}

Esta última circunstancia ha sido motivo de alguna crítica. Se argumenta que los TBIs han sido suscritos entre Estados. Sin embargo los beneficiarios son los inversionistas, no los Estados. Son los primeros los que obtienen protección en contra de ciertas acciones de los países anfitriones, los que tienen derechos bajos esos instrumentos, sin que se le imponga ningún tipo de deberes u obligaciones, ni siquiera aquellas llamadas "soft law", i.e., las que son solo enunciativas y no tienen carácter vinculante.

Los argumentos en contrario, son que no es inusual que los Estados se obliguen a través de instrumentos de Derecho Internacional Público en beneficio de personas de Derecho Privado, como sucede, por ejemplo en materia de derechos humanos, donde también se les da la posibilidad a aquellos a que demanden directamente a un Estado soberano ante instancias internacionales. Sin embargo, los derechos humanos, por su naturaleza y origen ontológico tienen una importancia

\footnotetext{
[consultada en febrero de 2015]. Disponible en: <https://treaties.un.org/doc/Publication/UNTS/ Volume\%201155/volume-1155-I-18232-English.pdf $>$.

10 Algunas de las críticas al Sistema Internacional de Protección de Inversiones Extranjeras se pueden encontrar en: SORNARAJAH, M. "Evolution or revolution in international investment arbitration? The descent into normlessness". In: BROWN, Chester and MILES, Kate (ed). Evolution in investment treaty treaty law and arbitration. Cambridge: Cambridge University Press, 2011. p. 631-657; SMIT, Hans. "The pernicious institution of the party-appointed arbitrator". Columbia FDI Perspectives. 2010, no 33; SACERDOTI, Giorgio. "Is the partyappointed arbitrator a "pernicious institution"? A reply to Professor. Hans Smit". Columbia FDI Perspectives. 2011, $\mathrm{n}^{\circ}$ 35; VAN HARTEN, Gus. 'The (lack of) women arbitrators in investment treaty arbitration". Columbia FDI Perspectives. 2012, n 59; SCHILL, Stephan W. "The public law challenge: Killing or rethinking international investment law?". Columbia FDI Perspectives. 2012, $\mathrm{n}^{\circ} 58$.
} 
que no necesariamente está presente en el Derecho Internacional de Inversiones. Los derechos humanos son reconocidos como intrínsecos a la condición humana e incluso anteriores a la misma existencia del Estado. Lo mismo no se podría decir del Derecho Internacional de Inversiones.

El segundo argumento en contrario es que no es cierto que los Estados no obtengan beneficios de esos tratados. Se argumenta que mediante el compromiso de obligarse por las reglas del Derecho Internacional de Inversiones, los Estados atraerán inversiones extranjeras.

La evidencia empírica a ese respecto no es concluyente. No se ha probado que suscribir un TBI garantiza la atracción de inversiones extranjeras. Por el contrario existen casos concretos que prueban que no suscribir un TBI o no ser parte de la Convención CIADI no ha impedido atraer inversiones. En América Latina el país que atrae la mayor parte de inversión extranjera que va al hemisferio es Brasil, el cual atrajo US \$ 64 mil millones en el año 2013, más del 20\% del total de inversión extranjero que recibió América Latina ${ }^{11}$. Sin embargo, Brasil no ha ratificado un solo TBI, ni es parte de la Convención CIADI.

Losinversionistas buscan oportunidades denegocio, circunstancias donde el beneficio sea mayor al costo. Si la oportunidad existeyla ecuación costo-beneficio es positiva, la inversión se hará. Encuestas realizadas a inversionistas demuestran que estos no toman en cuenta para decidir invertir en un país, si este ha suscrito o no un TBI con su país de origen. El clima de negocios del país donde se va a invertir es frecuentemente analizado por el inversionista y este está compuesto por aspectos tales como infraestructura, recursos naturales, recursos humanos, Estado de Derecho, entre otros. Que exista el riesgo de expropiación o que ante el maltrato del país anfitrión haya que demandar en tribunales locales, pueden no ser circunstancias determinantes en la decisión de invertir, si la oportunidad de negocios está presente y el beneficio esperado excede los costos. Más aún, los inversionistas cuentan hoy día con posibilidades de obtener seguros internacionales en contra de esos riesgos. Uno de ellos, por cierto, emerge de una Convención que también es parte del Derecho Internacional de Inversiones, la de la Organización Multilateral de Garantía de Inversiones (OMGI). De manera pues que el argumento según el cual hay que suscribir TBIs para que un país atraiga inversiones extranjeras, no tiene sustento fáctico.

No obstante la evidencia, los Estados continúan asumiendo obligaciones de cara a los inversionistas extranjeros en tratados internacionales. Algunos lo hacen con la intención de crear las

11 UNCTAD. World Investment Report 2014 [en línea]. New York and Geneva : UNCTAD, 2014. p. 62. [consultada en febrero de 2015]. Diponible en: <http://unctad.org/en/ PublicationsLibrary/wir2014_en.pdf>. 
condiciones para proteger a los capitales originarios de sus países, aunque hoy día la realidad sea que los capitales no tienen nacionalidad, siendo que los grandes inversionistas extranjeros, las multinacionales, atraen capitales de distintas partes del mundo a través de mercados de capitales o levantamiento privado de capitales.

Quienes usualmente han promovido la idea de tratados internacionales de protección a la inversión extranjera han sido los países desarrollados, donde, a pesar que el texto de los tratados se establecían obligaciones similares para todos los Estados partes, la realidad ha sido que son inversionistas catalogados como de la nacionalidad del país desarrollado quienes invertían en los países en desarrollo y no al revés. Sin embargo, en los últimos años se ha producido el fenómeno de multinacionales catalogadas con la nacionalidad de países en desarrollo, como CEMEX de México, Odebrecht de Brasil, Tata de India, CNPC de China, entre otras. Esta circunstancia, probablemente haya provocado el desarrollo de un buen número de TBIs entre países en desarrollo. Así, aunque en el pasado los países desarrollados tenían la motivación económica de crear condiciones de protección a los capitales de sus países bajo instrumentos de Derecho Internacional Público, en tanto que los países en desarrollo tenían la motivación económica de convertirse en polos de atracción de esos capitales foráneos a través de la asunción de compromisos bajos esos instrumentos de Derecho Internacional Público, la realidad actual ha sido una donde los países en desarrollo fungen a ratos tanto de exportadores como de importadores de capital. Así, en el año 2012 México exportó más de US \$ 20 mil millones ${ }^{12}$.

Más aún, con el auge de los llamados fondos de riqueza soberano -donde los fondos chinos y rusos encabezan la lista-los cuales no son otra cosa que fondos de inversión propiedad de los Estados soberanos, que invierten en una gran variedad de países, es posible que los países en desarrollo tengan más interés en suscribir más TBIs. Y lo que puede resultar interesante es que se comenzará a ver arbitrajes de multinacionales catalogadas de nacionalidad de un país en desarrollo en contra de países desarrollados.

Sea como sea, está visto que de las dos motivaciones económicas para suscribir los TBIs, solo se ha probado que una arroja resultados, la de protección del inversionista y la inversión extranjera.

En resumen, la protección de la inversión extranjera per se, bajo las condiciones privilegiadas del Derecho Internacional no tiene lógica, sino va acompañada de un quid pro quo en beneficio del país receptor. $O$ puesto en términos más precisos, de lo que se trata es de proteger a la inversión extranjera en tanto y cuanto es beneficiosa para el desarrollo de los países. En algunos casos las inversiones extranjeras no solo no han coadyuvado al desarrollo del país, sino que han sido contrarias al

$\overline{12 \text { Ibíd. en página } 6}$. 
desarrollo del país, como ha sucedido por ejemplo, con las inversiones que han sido nocivas al medio ambiente o cuando la inversión extranjera ha corrompido instancias públicas del país anfitrión. En consecuencia, una de las fallas del sistema actual de protección internacional a la inversión extranjera, es que no ha hurgado en la voluntad de las partes de los TBIs, para, haciendo una interpretación teleológica, extender la protección a la inversión en sintonía con el objetivo desarrollista de los Estados partes. Claro está, los árbitros solo podrían llegar hasta ciertos límites y es allí donde probablemente los negociadores de los TBIs pueda que hayan errado al no hacer explícito el objetivo de los países en lo que respecta a la protección y atracción de capitales foráneos. $\mathrm{Si}$, como indica la lógica, la raison d’etre de la política pública y la literatura más conspicua, el objetivo último de los países que suscriben los TBIs es fomentar su desarrollo interno, esa racionalidad detrás de la manifestación de voluntad, debe ser explorada por el intérprete -en este caso los árbitros-pero primero debe ser expresada en términos claros y precisos en los tratados.

\subsection{El abuso de la personalidad jurídica}

Otra crítica que se le hace al sistema de Derecho Internacional de Inversiones y que está relacionada con lo anterior tiene que ver con la nacionalidad del inversionista, en especial cuando se trata de una multinacional. Las multinacionales son una red de personas jurídicas registradas en distintos países con una gerencia común y un mismo fin, donde a través de figuras societarias y contractuales se toman las decisiones en un país, se realiza el financiamiento en otro país, se realiza el proceso productivo en otros países y se desarrolla o implementa la tecnología en otros tantos. En esos casos catalogar a una de las empresas de una $u$ otra nacionalidad puede ser un mero formalismo que no responde a la realidad. En puridad de conceptos la multinacional sería una unidad económica, solo que a efectos jurídicos serían diversas personas jurídicas separadas entre ellas por la personalidad jurídica y la apariencia de patrimonios y administración independientes.

En ese orden de ideas, si las distintas personas jurídicas que componen a la multinacional son diferentes, cada una de ellas debería tener protecciones internacionales separadas. Es más, las personas jurídicas de las multinacionales que se hayan registrado en el país anfitrión no deberían tener ninguna protección internacional, por cuanto se trataría de una persona jurídica nacional. Sin embargo, las multinacionales han obtenido a través de los TBIs un desconocimiento de la personalidad jurídica. Sí, pero uno que solo funciona en su beneficio y a los efectos de obtener la protección del Derecho Internacional de Inversiones. Así, los TBIs, de manera casi unánime, reconocen que las 
personas jurídicas relacionadas con un inversionista de nacionalidad del país de origen en términos de control, podrían ser consideradas inversionistas extranjeros, independientemente del lugar de registro e incluso si esa persona jurídica se ha registrado en el país anfitrión.

La crítica a este aspecto es que el mismo desconocimiento de personalidad jurídica no se consagra para los efectos de la responsabilidad del inversionista extranjero. En otras palabras, si una persona jurídica es responsable por algún daño ocasionado en el país anfitrión, el país anfitrión no podrá hacer responsable al resto de las personas jurídicas relacionadas con el inversionista extranjera, porque se trata de personalidades jurídicas diferentes e independientes con patrimonios separados y derechos y obligaciones disímiles.

Adicionalmente, la circunstancia que las multinacionales estén compuestas por personas jurídicas de tan variada nacionalidad ha originada cierta práctica abusiva, denominada "escogencia de tratado" o "treaty shopping", según la cual el inversionista busca el TBI que más le favorece de cara al país anfitrión y registra una persona jurídica en el país contraparte de ese tratado. La inversión extranjera se realiza a través de ese vehículo corporativo, a pesar que esa persona jurídica sea controlada por la casa matriz, la cual está registrada en otro país respecto al cual o bien no existe un TBI con el país anfitrión o bien es uno menos favorable. Peor aún, la persona jurídica a través de la cual se realiza la inversión, pueda que no tenga ningún nexo o presencia comercial significativa con el país en el cual se registra. Sin embargo, de cara al país anfitrión se le considera como inversionista extranjera de la nacionalidad del país de registro y con derecho a la protección que emerge del TBI respectivo. Un ejemplo típico de "escogencia de tratado", lo constituye la utilización de los TBIs con los Países Bajos.

Igualmente, motivo de crítica ha sido la interpretación amplia de la cláusula de nación más favorecida (NMF), incluida en los TBIs, a los fines de extender una super protección a los inversionistas extranjeros. Según la cláusula NMF, los inversionistas de los Estados partes al TBI tendrán derecho al trato más favorable que se le ofrezca a nacionales de otros países a través de otros tratados. Así, por ejemplo, si en un TBI entre los países $\mathrm{X}$ y $\mathrm{Z}$ no se otorgó consentimiento a someter disputas a arbitraje, pero el TBI en cuestión contiene una cláusula NMF, y existe otro TBI entre los Estados $\mathrm{Z}$ y W donde se otorgó consentimiento a someter las disputas a arbitraje, la interpretación amplia de la cláusula NMF podría ser usada para considerar que el trato otorgado a los inversionistas del Estado W en lo que respecta a sometimiento de disputas a arbitraje, también se debe extender a los inversionistas del Estado X en sus disputas con $\mathrm{Z}$, a menos que se haya hecho reserva expresa en el TBI. Como quiera que hay países como Argentina que ha suscrito 50 TBIs, mediante la utilización de la cláusula NMF, un inversionista 
podría estar facultado a lo mejor de cada uno de esos tratados, en una suerte de protección internacional a la medida. Cierto es que buena parte de los TBIs contienen más o menos disposiciones similares, al punto que algunos hablan del nacimiento del Derecho Internacional de Inversiones de corte consuetudinario, pero diferencias sutiles persisten, en aspectos tales como lapsos, definición de inversiones, obligaciones de los Estados, entre otras, que de aplicarse la cláusula NMF de manera irrestricta podrían dar lugar a más beneficios a los inversionistas extranjeros en desmedro de los intereses de los países receptores de la inversión.

\subsection{Limitaciones a la soberanía}

Nadie impone a los Estados que suscriban TBIs sean parte de otros instrumentos de Derecho Internacional de Inversiones. Son los Estados, quienes en pleno uso de su soberanía deciden limitar ciertos aspectos de políticas públicas, con fines ulteriores. Esas limitaciones asumen distintas formas. La más relevante es la relativa a las medidas equivalentes a expropiación.

Los TBIs contienen disposiciones según las cuales todas las medidas que tome el Estado anfitrión que de alguna forma se equiparen a la expropiación, deberán ser realizadas por razones de orden público, de manera no discriminatoria y compensadas de forma adecuada, oportuna y justa. Adicionalmente, en situaciones donde el Estado en uso de sus facultades regulatorias impone multas, impuestos o cumplimiento de requisitos, como por ejemplo ambientales, se ha considerado que se está en presencia de medidas equivalentes a la expropiación. En esos casos, se ha indicado que habrá una expropiación indirecta cuando se haya afectado la esencia del derecho de propiedad, de suerte que se le haya dejado inútil. Sin embargo, la mera existencia de esa limitación de cara a las posibilidades regulatorias del Estado anfitrión crea una carga que en algunos casos puede exceder los beneficios que el país recibe.

Lo mismo se puede decir de las disposiciones de los TBIs según las cuales los extranjeros tendrán derecho a un tratamiento similar a los nacionales en circunstancias similares. La definición de cuándo se está en presencia de circunstancias similares ha sido fuente de constantes disputas. Igualmente, la ambigua disposición de tratamiento justo y equitativo ha sido utilizada para proteger exageradamente al inversionista, llegando incluso al caso en que el sistema judicial del país anfitrión es evaluado por el tribunal arbitral para considerar si el tratamiento dispensado al inversionista fue justo y equitativo. También se ha usado ese criterio para proteger las igualmente ambiguas "expectativas legítimas" de los inversionistas. Tanto más se puede decir de las disposiciones de garantía y seguridad a los inversionistas, 
donde el Estado podría ser responsable por daños a la propiedad del inversionista causados por el hampa común. Y no faltaría hacer mención a la cláusula paraguas que dispone que el incumplimiento de una obligación contractual por parte del Estado, también será considerado una violación del TBI, con lo cual se potencia al inversionista con 2 acciones legales de naturaleza distinta en contra del Estado anfitrión: una de naturaleza contractual y la otra derivada del TBI.

Por otro lado, en virtud del Derecho Internacional de Inversiones solo los inversionistas extranjeros tienen del derecho de demandar al país receptor de la inversión ante un tribunal internacional. Los inversionistas privados locales carecen de ese derecho. Y esa discriminación puede ser motivo de malestar nacional o motivar a los nacionales a valerse de formas jurídicas y vehículos corporativos foráneos para poder enfrentar al país receptor en un terreno diferente al de los tribunales locales.

\subsection{Procedimientos arbitrales}

Hay quienes dicen que el arbitraje internacional de inversiones y el arbitraje internacional comercial se parecen tanto como un león marino se parece a un león de selva: solo en el nombre. Razón no les falta. Los temas con los que lidian los tribunales internacionales de arbitraje de inversión son diferentes de los que tocan a los tribunales internacionales de arbitraje comercial, tanto como lo son las partes. Medidas regulatorias, políticas e intereses públicos, soberanía, derechos de propiedad, entre otros, son temas que se entrelazan con regularidad en los arbitrajes de inversión entre Estados soberanos e inversionistas de nacionalidad extranjera. De ahí las demandas de transparencia y escrutinio público.

Que el concepto de arbitraje ha sido un traje tomado prestado por el Derecho Internacional de Inversiones Extranjeras, no es una exageración. Para los redactores del Convenio del CIADI la idea de tribunales permanentes para resolver controversias entre los Estados y los inversionistas extranjeros podría haber sido ineficiente. El volumen de las controversias que se esperaba no justificaba un órgano judicial permanente. En su lugar se creó una secretaría permanente sin la carga de un tribunal. En aquel momento parecía que el arbitraje era adecuado para las necesidades del naciente Derecho Internacional de Inversiones Extranjeras.

Pero los tiempos han cambiado. Los asuntos tratados por los tribunales arbitrales de inversión están en constante relación con el derecho internacional público de una manera que no encuentra paralelo en el arbitraje comercial internacional. Los principios de ius cogens, la interpretación de los tratados, la responsabilidad del Estado por daños causados a extranjeros, definición de inversión, la interpretación de 
la cláusula NMF, la nacionalidad, la cláusula paraguas, las diferentes versiones de expropiación, los estándares mínimos de tratamiento internacional, junto con el estado de necesidad, son algunos de los temas comúnmente tratados por los tribunales arbitrales de inversión.

$\mathrm{Si}$ a eso aunamos el argumento que ontológicamente el arbitraje ha sido desarrollado como un mecanismo alternativo a la resolución de disputas por tribunales, tenemos que en materia de inversiones extranjeras los arbitrajes de inversiones se han convertido en el status quo para resolución de disputas y no en la alternativa. Esto derivado, sobretodo del hecho que en el Derecho Internacional de Inversiones no existen tribunales permanentes frente a los cuales haya alguna alternativa que buscar. Por ello el objetivo de las críticas al actual sistema internacional de protección de inversiones extranjera -algunas de las cuales han activado reacciones de ciertos Estados soberanoses justamente buscar una alternativa al actual sistema de arbitraje internacional de inversiones.

La génesis de esas críticas es variada y se encuentra, entre otras, en la duración y costos de los procedimientos arbítrales de inversión. Así, en promedio los arbitrajes toman más de 2 años hasta que se produzca el laudo arbitral. Los gastos y honorarios de los arbitrajes de inversiones son exageradamente altos. Se ha considerado que honorarios por el orden de los US \$ 2 millones están en el rango bajo, con gastos por el orden de los US $\$ 400.000$ y se han visto casos de honorarios superiores a los US \$ 10 millones, de hecho superiores al monto final acordado en los laudos en beneficio de la parte vencedora ${ }^{13}$.

La designación de los árbitros es un punto de importante crítica. Es usual que los tribunales arbitrales de inversiones estén compuestos por 3 árbitros, donde cada parte designa a uno y luego los árbitros de común acuerdo escogen al presidente del tribunal. Los árbitros en principio no pueden ostentar la nacionalidad de ninguna de las partes, a menos que las partes acuerden lo contrario. En realidad, los árbitros casi nunca se ponen de acuerdo en la designación del presidente del tribunal y como consecuencia la secretaría de CIADI --cuando la disputa se ha presentado ante ese centro- designa al presidente (aunque de acuerdo a la Convención respectiva, la secretaría de CIADI propone un nombre a las partes para su consideración). Las designaciones, en todos los casos, pueden ser de árbitros que no estén incluidos en la lista de árbitros conformada por CIADI, a la cual cada país signatario ha nominado 4 árbitros. Como consecuencia de ello, tenemos que a pesar que la mayoría de los casos arbitrales tienen a un país en desarrollo como contraparte, la mayoría de los árbitros provienen de Estados Unidos y de Europa, con un porcentaje muy pequeño de árbitros originarios de países en desarrollo. Lo que es peor hay árbitros que son parte de tantos tribunales

13 UNCTAD. "Reform of Investor-State dispute settlement". IIA issues note. 2013, n 3, p. 4. 
arbitrales de inversiones bajo CIADI, que coloquialmente se habla de la creación de una suerte de club informal de árbitros de inversiones, al margen de la lista de CIADI, con árbitros que a ratos se desdoblan de su papel principal de abogados frente a otros tribunales arbitrales. He allí la génesis de una de las críticas más robustas a los tribunales arbitrales: su ilegitimidad y apariencia de imparcialidad.

Por otro lado, en contra de los laudos de los tribunales arbitrales de inversión no cabe la apelación. Por ello, con frecuencia las partes hacen uso del mecanismo de nulidad dispuesto en la Convención CIADI, según el cual en ciertos supuestos taxativos se puede pedir la nulidad del laudo, tales como error de constitución del tribunal, exceso de funciones, corrupción, violación grave de norma de procedimiento o carencia de expresión de los motivos en el laudo. Sin embargo, el procedimiento de creación del comité ad-hoc que decide la nulidad es igual de largo y oneroso que la constitución original del tribunal arbitral. En experiencias recientes donde se solicitó la nulidad de un laudo arbitral, el proceso tomó más de diez años hasta el momento cuando el laudo pudo ser ejecutado.

Los laudos arbitrales han sido de distinta naturaleza, algunos relativos a la objeción de jurisdicción, otros relativos a los méritos de los casos. Dentro de los primeros se ha confirmado la jurisdicción en algunas ocasiones y se ha denegado y desechado el arbitraje en otros por razones tales como que la disputa no era legal o no surgía directamente de la inversión, carencia de consentimiento, carencia de nacionalidad o falta de agotamiento de recursos internos.

Dentro de los segundos ha habido laudos arbitrales que han tratado los temas de expropiación, de expropiaciones indirectas, de tratamiento nacional en circunstancias similares, de tratamiento justo y equitativo, de cláusula paraguas y de garantía de protección y seguridad, así como el análisis de las medidas de emergencia económica, entre otros.

En los laudos han prevalecido los Estados en algunas ocasiones y en otras ocasiones los inversionistas. El porcentaje de laudos conocidos es aproximadamente $51 \%$ a favor de los inversionistas y $48 \%$ a favor de los Estados ${ }^{14}$.

Sin embargo, uno de las críticas que también se escucha del lado de los inversionistas es la falta de consistencia por parte de los tribunales arbitrales. Con frecuencia se aplican criterios diferentes a hechos similares. En otras palabras, los precedentes de los tribunales arbitrales, aunque no son obligatorios, tampoco sirven de guía, creando incertidumbre entre todos los usuarios del sistema de arbitraje de inversiones. Ha habido tribunales arbitrales que han llegado a

14 ICSID Caseload Statistics, 2014-2. [consultada en febrero de 2015]. Disponible en: $<$ https:// icsid.worldbank.org/apps/ICSIDWEB/resources/Documents/ICSID $\% 20$ Web\%20Stats\%20 2014-2\%20(English).pdf $>$. 
conclusiones diferentes y hasta opuestas a otros tribunales arbitrales que han analizado hechos similares bajo los mismos o similares TBIs. Así ha ocurrido con los temas de la definición de la cláusula paraguas, el alcance de la cláusula NMF y la definición de la nacionalidad del inversionista cuando se trata de una empresa extranjera propiedad de inversionistas locales.

Del lado de los inversionistas también se ha escuchado crítica sobre la cuantía de los laudos. Cuando los inversionistas han resultado vencedores, con frecuencia los montos de compensación acordados son mucho menos de la mitad de lo solicitado.

Algunas palabras hay que decir en relación a lo dilatado del proceso de toma de decisiones. Una vez concluido el procedimiento los árbitros no tienen fecha límite para la presentación del laudo y con frecuencia toma exagerado período de tiempo conocer de la decisión. Y aunque las partes tienen fechas fatales para la realización de las actuaciones, las mismas no existen para las decisiones de los árbitros.

Los laudos emitidos por un tribunal arbitral de CIADI, cuando son en contra del Estado, se pueden ejecutar en cualquiera de los países signatarios de la Convención. Decisiones de comités ad-hoc en el contexto de demandas de nulidad de laudos arbitrales, han indicado que los laudos son ejecutables incluso si estuviera pendiente la decisión de una nulidad del laudo. Según esas decisiones, la ejecución del laudo solo se podría suspender si el Estado presenta caución por la totalidad del monto acordado en el laudo en un lapso perentorio.

Algunos inversionistas beneficiados por laudos que no han sido ejecutados o incluso antes que hayan sido emitidos los laudos, han vendido sus derechos bajo los arbitrajes a otros inversionistas. A la cual hay que agregar la práctica de financiamiento de los arbitrajes por terceras personas, en algunos casos por fondos de inversión que compartirían un porcentaje de la posible compensación: una suerte de "pacta cuota litis". Todo esto ha generado un comercio de los derechos de los inversionistas bajo el Derecho Internacional de Inversiones. Así, los Estados pueden terminar en ocasiones cancelando laudos arbitrales a personas diferentes de aquellas respecto a las cuales se presentó la demanda de arbitraje; personas que podrían no tener la nacionalidad de ninguno de los Estados partes en el TBI o que podrían tener la nacionalidad del Estado anfitrión. Nada en el Derecho Internacional de Inversiones, ni los TBIs, ni en la Convención CIADI impide que las prácticas de cesión de los derechos en los arbitrajes de inversiones sean realizadas.

\section{PROPUESTAS DE REFORMAS}

Antes de promover reformas, los países han de tomar una decisión 
crucial de políticas públicas: se protege a la inversión extranjera en la expectativa que con eso será atraída o no. Si se le protege, quizá convenga implementar medidas e incluso reformas que hagan del sistema algo más justo. Algunas de esas medidas son reactivas y otras son proactivas. Unas tienen que ver con la defensa y otras con la negociación.

\subsection{Mecanismo de asesoría}

De forma similar a como existe en la Organización Mundial de Comercio (OMC), se podría crear un mecanismo que asesore y asista a los países tanto en la defensa como en la prevención de disputas de inversiones. Así, en materia de defensa los países deben coordinar la defensa de los arbitrajes con acciones legales locales. Con frecuencia las acciones legales en los tribunales locales pueden traducirse en beneficios en los tribunales arbitrales. Por ejemplo, en algunos países los contratos de interés público no pueden ser objeto de arbitraje internacional. Para que un contrato sea declarado de interés público se precisa que haya sido declarado como tal por un tribunal competente. Hecho eso, el tribunal arbitral podría perder la jurisdicción.

La designación de los árbitros se puede hacer de manera coordinada con países que estén en condiciones similares. Con frecuencia se designa árbitros que no conocen el sistema legal del país, ni su cultura y a veces ni siquiera el idioma. Una estrategia coordinada entre países que estén en circunstancias parecidas, puede contrarrestar la práctica perniciosa de designar árbitros que desconocen las realidades de los países partes de la disputa. Igualmente se podrían presentar quejas de varios países ante la secretaría CIADI a los fines que cuando ésta deba designar a los presidentes del tribunal arbitral, designe a árbitros de la lista de países con características equivalentes a las del país parte en la disputa.

El desarrollo de una base de datos de jurisprudencia sobre los casos en que se han tratado las objeciones de jurisdicción es importante. De allí se puede extraer el conocimiento necesario para poder terminar con algunos arbitrajes en la etapa preliminar. Lo mismo se podría decir de la jurisprudencia sobre temas de fondo. Igualmente, el desarrollo de un equipo local de defensa de esos casos es necesario. Argentina ha desarrollado su propio equipo para la defensa de los casos de arbitraje de inversiones. En algunos casos han triunfado y ello les ha permitido ahorrar fondos en los altos honorarios que usualmente se observan en los arbitrajes de inversión.

En términos proactivos, conviene desarrollar iniciativas que impidan el desarrollo de más casos o cuando menos minimicen sus efectos. Así, por ejemplo el desarrollo de una ley de inversiones local que imponga obligaciones a los inversionistas y haga responsables a todo el grupo inversionista, puede ser de utilidad. Igualmente, algunas 
iniciativas regionales se han tratado de desarrollar a fin de ayudar a países en desarrollo en la defensa de arbitrajes de inversión. En Centro América se trató de crear un fondo que financie la asistencia técnica legal local, a la par que contribuya a pagar los honorarios de los abogados internacionales cuando haga falta. El problema con esta iniciativa estribó en que los mismos países debían contribuir con recursos propios en la creación del fondo, lo cual probablemente lo hizo inviable.

Igualmente, desde el punto de vista proactivo, una revisión de toda la política de inversión extranjera es crucial. Por ejemplo, los TBIs se pueden renegociar. Las siguientes reformas se pueden incorporar:

- Creación de tribunales de apelación de los laudos arbitrales;

- Condicionar el consentimiento arbitral o no otorgarlo;

- Imponer obligaciones al inversionista, tales como las de responsabilidad social;

- Desconocer la personalidad jurídica del grupo inversionista cuando se cause daño al país receptor;

- Establecer expresamente que el propósito de los Estados y el objetivo del TBI es atraer inversiones en tanto y cuanto sean beneficiosas para el desarrollo del país;

- Negar protección a las inversiones que no sean beneficiosas para el desarrollo o no cumplan con las leyes del país;

-Definir los supuestos de expropiaciones y los de tratamiento injusto y no equitativo.

Los países también podrían limitar el tipo de disputas que pueden ser objeto de disputas. Así lo hizo Ecuador en CIADI, donde expresamente indicó que las disputas relativas a recursos naturales no serían objeto de consideración de los tribunales arbitrales de ese centro.

\subsection{Inclusión de fases preclusivas de arreglos amigables y de mediación antes del arbitraje}

Esta propuesta consistiría en el desarrollo de disposiciones contractuales, de tratados o legales, según las cuales una vez que haya surgido la disputa, el inversionista y el Estado deberán iniciar dos períodos previos, uno de arreglo amigable y otro de mediación, sin cuyos agotamientos no podrán pasar a la fase siguiente de arbitraje ${ }^{15}$. A tales efectos deberán demostrar que intercambiaron comunicaciones que denoten la existencia de una disputa, a partir de cuyas fechas se inicia la fase de arreglo amigable con un tiempo perentorio. Concluida esa fase, sin éxito, las partes podrán iniciar un proceso formal de mediación profesional por determinado período de tiempo. Y solo

15 How to Prevent and Manage Investor-State Disputes: Lessons from Peru, Best Practices in Investment for Development Series (United Nations, New York and Geneva, 2011) en página 32 . 
después de concluida la segunda fase, las partes podrán someter la disputa a arbitraje.

A diferencia de lo que ocurre actualmente donde muchos tribunales arbitrales obvian los requisitos previos al arbitraje que existen en muchos tratados de protección de inversión tales, como períodos de arreglos amigables y períodos en tribunales locales, bajo la excusa que ello sería "fútil" o que es un asunto de admisibilidad y no de jurisdicción; en la implementación de esta propuesta se indicaría expresamente -en los instrumentos donde se consagre- que las fases anteriores al arbitraje han de ser agotadas de forma obligatoria.

La ventaja de esta propuesta es que crea condiciones para que las partes se comuniquen, negocien y encuentren soluciones propias o mediadas, a la par que la disputa pueda ser solucionada a bajo costo. Sin embargo, por otro lado, esta propuesta tiene la desventaja que, de no resultar exitosa la negociación y la mediación, tiempo y costos adicionales habrán de ser sumados a las partes contendientes.

\subsection{Desarrollo de un mecanismo de apelación de las decisiones de los tribunales que conozcan la disputa de inversiones}

Algunas opciones se han propuesta, tales como tribunales permanentes de apelación los cuales revisarían los laudos arbitrales. En esa línea algunos TBIs contienen disposiciones programáticas que abren la oportunidad para que los Estados partes negocien la creación de esos entes. Otra opción podría ser la asignación de la apelación a dos o tres cortes de apelación en diferentes países suramericanos ${ }^{16}$. Esta opción podría funcionar así: las disputas podrían ser resueltas por un tribunal arbitral como ocurre ahora y mediante tratado se podría establecer que la apelación se podría presentar ante un tribunal internacional especialmente creado o ante las máximas instancias judiciales de países debidamente definidos en el tratado, que sean diferentes a las partes en disputa y ajenos a la controversia, a elección de las partes.

Esta opción tiene la ventaja que provee legitimidad a quienes deciden la disputa; estabilidad al tribunal; consistencia a sus decisiones; neutralidad en la decisión, e incluso, podría rebajar los costos. Una modalidad intermedia es la de consagrar la posibilidad -a través de los mismos tratados en los que se establezca esta modalidad de apelación- de que las cortes que conozcan de estos recursos, puedan estar constituidas con jueces asociados -vale decir designados por las partes- conjuntamente con los jueces titulares.

16 Vid RONDÓN DE SANSÓ, Hildegard. "Vías sustitutivas del arbitraje internacional de inversión (Alternative ways to international investment Arbitration)". Quinto Día [en línea]. 2012. Disponible en: <http://www.quintodia.net/pais/2473/ vias-sustitutivas-del-arbitraje-internacional-de-inversion $>$. 
Las ventajas de la aplicación de este sistema es hacerle perder al inversionista el temor por la falta de imparcialidad de los jueces nacionales, ya que los tribunales se constituirían con juristas independientes. Paralelamente, una decisión de un tribunal de otro país, será más fácil de aceptar por parte del Estado a los efectos de una ejecución voluntaria.

Una desventaja obvia es que los jueces podrían no conocer el Derecho aplicable a la disputa.

\subsection{La creación de un tribunal de inversiones regional}

Los tribunales permanentes de inversiones se crearían a través de acuerdos internacionales y estarían compuestos por jueces. Una modalidad sugerida para estos tribunales permanentes es que los jueces formen diferentes tribunales en un centro a los cuales las demandas podrían ser asignadas al azar, apartándose de esta manera, del sistema de árbitros postulados por las partes ${ }^{17}$. Esto aseguraría en caso de un conflicto de intereses que se elija a otro juez del centro. Los jueces serían designados a los tribunales previamente por el centro de resolución de conflictos y serían activados con la presentación de una reclamación. Jueces suplentes también podrían ser nombrados para hacerse cargo cuando, debido a los conflictos de intereses $u$ otros motivos, un juez no pueda ser parte de un tribunal. Por lo tanto, los jueces no serían excluidos de la realización de otras actividades profesionales antes de ser asignados a un caso. Honorarios serían recibidos por los jueces sólo por los casos en que participen, evitando así gastos innecesarios en salarios de jueces.

El formato utilizado por la Comisión Interamericana de Derechos Humanos puede ser una fuente de inspiración. Los miembros son nombrados por un período de tiempo y los casos se asignan de acuerdo a las reglas internas. Los jueces de la misma nacionalidad de las partes en litigio quedarían inhibidos automáticamente.

Por supuesto, las personas designadas para el tribunal de inversión tendrían que cumplir con ciertos requisitos éticos y profesionales, como tener un conocimiento suficiente del Derecho Internacional de Inversiones. Esta estructura garantiza tanto que los inversionistas estén satisfechos con el nivel de competencia de los jueces y que los Estados estén satisfechos con la estabilidad, la transparencia y la previsibilidad del marco de resolución de las disputas.

Los tribunales permanentes de inversión podrían funcionar en el marco de un centro o entidad internacional ad hoc. El centro en el

17 NOWROT, Karsten. "International Investment Law and the Republic of Ecuador: from arbitral bilateralism to judicial regionalism". Beitrträge zum Transnationalen Wirtschafsrecht. 2010, p. 46. 
que se alojen los tribunales podría ser administrado por una secretaría permanente, que podría tener también responsabilidades de promoción y educación sobre el funcionamiento y la estructura de los tribunales y de los recursos disponibles en el mismo. La secretaría también podría tener responsabilidades en la promoción del uso del centro de vis-â-vis los Estados y los inversionistas, y abogar por el consentimiento para someter las controversias de inversión a estos tribunales.

Teniendo en cuenta la tendencia de utilizar otros mecanismos alternativos de resolución de conflictos, el centro también podría prestar servicios de mediación y conciliación a través de profesionales (diferentes de los jueces). Alentar el uso de estos mecanismos podría ser una buena manera de promover los beneficios del centro y el potencial uso de sus tribunales permanentes de inversión.

Las partes en disputa tendrían la opción de decidir o no resolverla ante esos tribunales permanentes de inversión. Y el consentimiento del Estado se concedería, como ahora, a través de tratados, leyes, notificaciones o presentación de los reclamos.

Los tribunales permanentes de inversión podrían ser financiados por los Estados, como lo hacen en la OMC o en otros tribunales permanentes regionales. En perspectiva, muchos Estados podrían comparar la cantidad pagada en los costos del arbitraje de inversión frente a los costos de financiación de los tribunales permanentes, tal vez dando un resultado favorable a estos últimos.

Al principio, estos tribunales probablemente hayan de competir con los tribunales de arbitraje a los que ya se ha concedido el consentimiento. Pero con el tiempo y en la medida que la reputación de estos nuevos tribunales evolucione, estarán en condiciones de atraer más reclamos. Además, en virtud de futuros tratados, los Estados podrían formalmente otorgar su consentimiento para someter las controversias a los tribunales en forma exclusiva o alternativa ${ }^{18}$.

Los inversionistas a su vez estarían motivados a buscar a un tribunal de inversiones permanentes por razones de neutralidad, coherencia, previsibilidad y menores costos.

Cabe destacar que la idea de tribunales de inversión permanente en Derecho Internacional de Inversiones tiene un precedente en el Acuerdo Unificado para Inversiones de capital árabe en los Estados árabes ${ }^{19}$. Este acuerdo establece una Corte de Inversiones árabe que se compone de al menos cinco jueces y varios miembros de la reserva, cada uno con una nacionalidad árabe diferente, que son elegidos por un órgano superior, el Consejo, a partir de una lista de especialistas

18 GARCIA-BOLIVAR, Omar E. "Has the time arrived for permanent investment tribunals?" International Investment Law [en línea]. Disponible en: <http://works.bepress.com/ omar_garcia_bolivar/15>.

19 LEAGUE OF ARAB STATES. "Unified Agreement for the Investment of Arab Capital in the Arab States”. In: Economic Documents nº 3. Tunis: League of Arab States, 1982. 
jurídicos árabes elaborados específicamente para tales propósito; dos de éstos han de ser nombrados por cada Estado Parte de los que tienen las calificaciones académicas y morales para asumir posiciones jurídicas de alto rango. El Consejo nombra al presidente de la Corte de entre los miembros de la Corte. Los miembros de la Corte sirven por períodos renovables de tres años a tiempo completo, cuando el trabajo lo requiere.

La creación de tribunales de inversión permanentes podría parecer una tarea titánica en el momento que requiere consenso político y maniobras diplomáticas de muchos Estados. Sin embargo, el consenso no tendría que ser universal: un tribunal de inversión podría comenzar como una iniciativa multilateral o regional, con un mecanismo de ingreso para los Estados que deseen unirse.

En América del Sur actualmente, existen 21 acuerdos internacionales de inversión entre los países de la Unión de Naciones Suramericanas (UNASUR) Argentina, Bolivia, Brasil, Chile, Colombia, Ecuador, Guyana, Paraguay, Perú, Surinam, Uruguay y Venezuela; 4 acuerdos internacionales de inversión entre los países que son miembros del ALBA, la Alternativa Bolivariana para las Américas, que comprende Antigua y Barbuda, Bolivia, Cuba, Dominica, Ecuador, Honduras, Nicaragua, San Vicente y las Granadinas, y Venezuela, y 4 de inversión internacional acuerdos entre países que son miembros del mercado común de América del Sur, MERCOSUR, que comprende Argentina, Brasil, Paraguay, Uruguay y Venezuela.

Un tribunal de inversiones regional podría estar formado, por ejemplo, por la UNASUR, por ALBA o por el MERCOSUR.

Actualmente esta es la propuesta que pareciera estar recibiendo más apoyo en el ámbito diplomático de algunos países de América del Sur y la que posiblemente tenga más fortalezas de encarar el asunto clave: un foro neutral, profesional y estable para resolución de las disputas de inversiones ${ }^{20}$.

\section{CONCLUSIÓN}

El actual sistema de protección internacional de inversiones extranjeras cumplió un ciclo. Son muchas las voces que claman por cambios y muchas las acciones de los Estados cada vez más concretas hacia un nuevo orden de cosas.

Que el actual sistema haya sido beneficioso en su momento, no se discute. Que haya tenido la bondad de evolucionar de un sistema donde intereses políticos podían llevar a resultados no deseados, tampoco se

20 Vid, Protocolo Constitutivo del Centro de Mediación y Arbitraje de la Unión de Naciones Suramericanas "UNASUR" en materia de inversiones. Disponible en: <http:// www.unasursg.org/uploads/4f/d0/4fd027384196e 5 e0073e $36 \mathrm{cf} 76 \mathrm{cffc} 6 \mathrm{~d} /$ Protocoloconstitutivo-Centro-de-Mediacion-y-Arbitraje-en-materia-de-inversion.pdf > . 
discute.

El asunto a debatir es cómo hacer que ese sistema migre a uno que sea balanceado y ajustado al nuevo devenir. Uno donde las decisiones de los Estados puedan ser revisadas de forma legítima, neutra e independiente, en tanto se tengan en cuenta las obligaciones de los inversionistas de forma grupal y no como collage de muchas personas jurídicas de diversas nacionalidades.

En ese continuum son muchas las propuestas que se pueden hacer. Algunas han sido mencionadas aquí. De ellas la creación de tribunales permanentes de inversión parece encomiable. En América Latina un tribunal de esa naturaleza puede extenderse a más de 29 acuerdos internacionales de inversión y por lo tanto, abrir la posibilidad para que inversionistas de varios Estados de la región tengan otro foro para resolver las disputas de inversiones de un valor superior a los US \$292 mil millones ${ }^{21}$.

Sea como fuere, lo significativo es que ante la crisis del sistema internacional de solución de disputas de inversiones, la creatividad se impone en aras de la equidad y del desarrollo sostenible social y económico de los pueblos del mundo.

\section{REFERENCIAS BIBLIOGRÁFICAS}

GARCÍA-BOLÍVAR, Omar E. "Sovereignty vs. Investment protection: back to Calvo?" ICSID Rev. 2009, n² 2, p. 446.

GARCIA-BOLIVAR, Omar E. "Has the time arrived for permanent investment tribunals?" International Investment Law [en línea]. Disponible en: <http://works.bepress.com/omar_garcia_bolivar/15>.

ICSID. Caseload Statistics, 2014-2 [consultada en febrero de 2015]. Disponible en: <https://icsid.worldbank.org/apps/ICSIDWEB/resources/ Documents/ICSID\%20Web\%20Stats\%202014-2\%20(English).pdf $>$.

ICSID. Convención del Centro Internacional de Arreglo de Disputas de Inversiones. (10 Sept. 1964), 1 U.S.T. 1270, 4 I.L.M. 524. Disponible: <https://icsid.worldbank.org/ICSID/StaticFiles/basicdoc/CRR_ English-final.pdf $>$ [consultada en febrero de 2015].

LEAGUE OF ARAB STATES. "Unified Agreement for the Investment of Arab Capital in the Arab States". In: Economic Documents $n^{\circ} 3$. Tunis: League of Arab States, 1982.

NACIONES UNIDAS. Carta de los Derechos y Deberes Económicos de los Estados, 12 de diciembre de 1974. Resolución 3281 (xxix) de la Asamblea General de la ONU [en línea]. [consultada en febrero de 2015] Disponible en: <http://biblio.juridicas.unam.mx/libros/1/353/57.pdf>. NACIONES UNIDAS. Convención de Viena sobre el Derecho de los

21 El monto de la inversión extranjera directa en 2013 en esa región.Ver UNCTAD. World Investment Report 2014. New York and Geneva, 2014. p. 62 [consultada en febrero de 2015]. Diponible en: <http://unctad.org/en/PublicationsLibrary/wir2014_en.pdf>. 
Tratados, artículo 31. [consultada en febrero de 2015].Disponible en: $<$ https://treaties.un.org/doc/Publication/UNTS/Volume\%201155/ volume-1155-I-18232-English.pdf $>$.

NOWROT, Karsten. "International Investment Law and the Republic of Ecuador: from arbitral bilateralism to judicial regionalism". Beitrträge zum Transnationalen Wirtschafsrecht. 2010, p. 46.

SACERDOTI, Giorgio. "Is the party-appointed arbitrator a "pernicious institution"? A reply to Professor. Hans Smit". Columbia FDI Perspectives. $2011, \mathrm{n}^{\circ} 35$.

RONDÓN DE SANSÓ, Hildegard. "Vías sustitutivas del arbitraje internacional de inversión (Alternative ways to international investment Arbitration)”. Quinto Día [en línea]. 2012. Disponible en: <http://www. quintodia.net/pais/2473/vias-sustitutivas-del-arbitraje-internacionalde-inversion $>$.

SCHILL, Stephan W. "The public law challenge: Killing or rethinking international investment law?". Columbia FDI Perspectives. 2012, n 58.

SMIT, Hans. "The pernicious institution of the party-appointed arbitrator". Columbia FDI Perspectives. 2010, n 33.

SORNARAJAH, M. "Evolution or revolution in international investment arbitration? The descent into normlessness". In: BROWN, Chester and MILES, Kate (ed). Evolution in investment treaty treaty law and arbitration. Cambridge: Cambridge University Press, 2011. p. 631-657. UNCTAD. "Reform of Investor-State dispute settlement". IIA issues note. $2013, \mathrm{n}^{\circ} 3$, p. 4.

UNCTAD. World Investment Report 2014 [en línea]. New York and Geneva: UNCTAD, 2014. p. 62 [consultada en febrero de 2015]. Diponible en: <http://unctad.org/en/PublicationsLibrary/wir2014_ en.pdf $>$.

VAN HARTEN, G. "A Case for International Investment Court" [en línea]. In: Society of International Economic Law (SIEL) Inaugural Conference 2008 Paper, (June 30 2008). [consultada febrero de 2015]. Disponible en: <http://papers.ssrn.com/sol3/papers.cfm?abstract_ $\mathrm{id}=1153424>$.

VAN HARTEN, Gus. "The (lack of) women arbitrators in investment treaty arbitration”. Columbia FDI Perspectives. 2012, n 59. 